\title{
INFLUENCIA DEL DETERIORO DEL CEPILLO DENTAL SOBRE LA HIGIENE BUCAL DE ESCOLARES
}

\author{
${ }^{1}$ Liliana Patricia Acevedo Piñeres, ${ }^{2}$ Clara Johana Caicedo Rico, ${ }^{3}$ Claudia Milena León Castro, ${ }^{4}$ Sonia Constanza Concha Sánchez \\ ${ }^{1}$ Estudiante X Semestre F. de Odontología U. Santo Tomás, Colombia. \\ ${ }^{2}$ Odontóloga U. Santo Tomás, Especialista en Educación y Comunicación para la Salud, MSc. Epidemiología U. Industrial de Santander, \\ Docente U. Santo Tomás, Colombia.
}

Autor responsable de la correspondencia: Clara Johanna Caicedo Rico

Correo electrónico: claris2486@hotmail.com

\section{RESUMEN}

Objetivo: determinar el efecto del deterioro del cepillo sobre la higiene bucal en los escolares matriculados en segundo grado de la Concentración Yira Castro evaluados durante el segundo semestre del 2009.

Materiales y métodos: se desarrolló un estudio descriptivo de seguimiento a una cohorte con 59 escolares en edades entre 6 y 9 años. Se incluyeron variables sociodemográficas, capacidad funcional motora, actitud del niño a la hora de cepillarse y las relacionadas con la higiene bucal como el deterioro del cepillo de dientes y la cantidad de placa acumulada. Para el análisis estadístico univariado se calcularon medidas de resumen según la naturaleza de las variables, para el bivariado se comparó la higiene bucal y el deterioro del cepillo según control realizado mediante test de Anova para medidas repetidas. Se correlacionó la higiene bucal con el deterioro del cepillo mediante el coeficente de correlación de Spearman, se estableció la asociación de higiene bucal con sus variables explicatorias mediante test de chi cuadrado, test exacto de Fisher y prueba t de Student y se efectúo análisis de sobrevida al deterioro de los cepillos Se consideró significativo un valor de $\mathrm{p}<0,05$.

Resultados: el promedio de placa dentobacteriana que representó un nivel de higiene bucal malo y regular fue de $(2,6 \pm 0,3$ y $1,7 \pm 0,4)$ y de $(2,2 \pm 0,6$ y $1,5 \pm 0,5)$ antes vs después para el primer y cuarto control respectivamente; los niveles de placa antes vs. después registraron diferencias estadísticamente significativas en los cuatro controles. Al analizar la correlación entre el nivel de higiene bucal y el deterioro del cepillo se evidenciaron bajos niveles de correlación entre estos dos aspectos que oscilaron entre $-0,04$ y 0,35 Conclusiones: no existió relación entre el deterioro del cepillo dental y el nivel de higiene bucal. El problema relacionado con la higiene bucal fue una mala técnica para realizar su cepillado. [Acevedo LP, Caicedo CJ, León CM, Concha SC. Influencia del deterioro del cepillo dental sobre la higiene bucal de escolares. Ustasalud 2012; 11: 79 - 87]

Palabras clave: Cepillado dental, Higiene bucal, Placa dental

\section{INFLUENCE OF THE TOOTHBRUSH WEAR ON ORAL HYGIENE IN STUDENTS}

\begin{abstract}
Objective: to determine the effect of the toothbrush wear on oral hygiene in students enrolled in second grade at Concentración Yira Castro evaluated during the second period of 2009.

Methods: an observational following study was done with a 59 school children aged 6 to 9 years old cohort. The variables were: sociodemographic aspects, functional motor ability, attitude of the child at the time of brushing, oral hygiene-related with the toothbrush wear and the amount of dental plaque. The statistical analysis plan included to calculate the summary measures. The analysis to compare the oral hygienic and the toothbrush wear in each control a repeated ANOVA test was applied. The oral hygienic and toothbrush wear correlate was studied with Spearman correlate coefficient. The association the oral hygienic with other variables was evaluated with Chi square, Fisher exact and the $t$ Student test, and the survival analysis for toothbrush wear was done. For all tests, $p<0.05$ was considered statistically significant..

Results: the average for dental plaque representing a bad to regular oral hygiene were $(2.6 \pm 0.3$ y $1.7 \pm 0.4)$ y de (2.2 \pm 0.6 y $1.5 \pm 0.5)$ before and after brushing by the first and last control, respectively. There was statistically significant differences between tootbrushing before and after in all the four controls. It was showed low levels of correlations between the level of oral hygiene and the toothbrush wear which ranged from -0.04 to 0.35

Conclusions: there was no relationship between the toothbrush wear and the oral hygiene level. The problem related to oral hygienic in the students that were including in this study was a bad tooth brushing technique.
\end{abstract}

Key words: Toothbrushing, Oral hygiene, Dental plaque

Recibido para publicación: junio 11 de 2012. Aceptado para publicación: septiembre 10 de 2012. 


\section{INTRODUCCIÓN}

En el ámbito mundial, la caries dental se mantiene como la enfermedad más frecuente en los niños de los niveles socioeconómicos más bajos. ${ }^{1}$ En Colombia, la población infantil más vulnerable tiene un riesgo incrementado a desarrollar patologías dentales como caries dental y periodontopatías; en Bogotá en el año 1999 se realizó un estudio en una población de niños entre 0 y 5 años que reportó una prevalencia de caries dental del 54\%, en el 2000 se realizó un estudio similar en el que se observó una frecuencia de caries dental aún más alta (73\%). ${ }^{2}$

La buena higiene bucal se fundamenta en el uso adecuado del cepillo dental, si no hay un correcto manejo de éste se presenta una predisposición a desarrollar todo tipo de patologías dentales que inician principalmente por el acumulo de placa bacteriana. La formación de la placa es un fenómeno fisiológico en el ambiente bucal y por esta razón no se puede prevenir totalmente. Además, es un factor etiológico para el desarrollo de caries dental y de enfermedad periodontal; por esto es importante controlar la remoción de placa. ${ }^{3-5}$

La principal causa asociada a las alteraciones dentales es la mala remoción de la placa bacteriana, que se refleja con una deficiente higiene bucal y se relaciona directamente con un cepillado dental inadecuado. Un correcto cepillado dental es fundamental para la reducción de la placa bacteriana; un buen cepillado dental es una manera fácil, efectiva y de bajo costo para lograr una buena higiene bucal y, por ende, una óptima salud bucal.,7

El tema del deterioro del cepillo de dientes y su influencia en la remoción de placa ha sido estudiado y aún existen pocos estudios sobre su relación. La literatura reporta que este deterioro no sólo se produce por el uso del cepillo sino que otros factores como la inadecuada técnica de cepillado o la fuerza excesiva pueden influir. Daly y colaboradores sugirieron que el desgaste de los cepillos dentales depende fundamentalmente de cómo se use el cepillo; aquellas personas que hacen un cepillado fuerte deberán renovar su cepillo más frecuentemente que las que realizan una fuerza más ligera durante el cepillado. ${ }^{8}$ Van der Weijden y colaboradores afirmaron que no hay una relación lineal entre la fuerza y la eficacia en el cepillado y que la fuerza que se le debería aplicar al cepillo no debería ser mayor a los $4 \mathrm{~N}^{9,10}$

Una buena higiene bucal puede verse afectada también, por la motivación que tenga el individuo para hacerla; la motivación se define como el interés que tiene una persona para enfrentar algo y puede verse condiciona por factores ambientales, personales y conductuales y que varía de un sujeto a otro. ${ }^{11}$ En la práctica odontológica es importante la motivación y la educación que se le proporciona para motivar al paciente con el propósito de promover hábitos de autocuidado bucodental. ${ }^{12}$

Algunos estudios demuestran la importancia y los buenos resultados que se obtienen en los niños cuando se implementan la motivación y la educación a los padres acerca de los hábitos de higiene bucal desde los primeros meses. ${ }^{13,14}$ A pesar de la importancia que puede tener la motivación sobre los resultados relacionados con la higiene bucal, en la literatura revisada no se encontró una forma de medirla; aunque una prueba situacional podría constituirse en una alternativa que permite observar cómo reacciona un individuo ante un estímulo y en este caso frente al interés de realizar y mantener un buen cepillado dental.

Otro aspecto relacionado con el deterioro del cepillo es la motricidad fina la cual hace referencia al desarrollo motor relacionado con los movimientos que exigen precisión. Es importante anotar que para que la motricidad fina se evidencie es necesaria la coordinación dinámica general; esto significa que el desarrollo motor se registra inicialmente a nivel de cabeza, tronco, piernas y brazos. Posteriormente, el desarrollo se manifiesta a nivel de codo y muñeca y por último en el movimiento fino de los dedos. La motricidad fina es un concepto complejo compuesto por varios criterios que incluyen el tono muscular, la disociación motriz, la coordinación visomotriz, la coordinación intermanual y la planeación motora. ${ }^{15}$

Con esta base, el objetivo de esta investigación fue determinar el efecto del deterioro del cepillo sobre la higiene bucal en los escolares matriculados en segundo grado de la Concentración Yira Castro sede D evaluados durante el II semestre del 2009.

\section{MATERIALES Y MÉTODOS}

Se realizó un estudio observacional descriptivo de seguimiento a una de cohorte de escolares que cursaban segundo de primaria, cuyas edades oscilaron entre los seis y los nueve años, vinculados a la Concentración Yira Castro. Se excluyeron a los niños con discapacidades físicas y/o mentales, con trastornos del lenguaje y los que se negaron a participar aun contando con la aceptación de sus padres; de esta forma la muestra la integraron 59 niños.

Se incluyeron en el estudio las variables sociodemográficas como edad y sexo. La variable actitud del niño a la hora de cepillarse la cual se midió con una prueba situacional. La variable habilidad mo-tora fina la definió una terapeuta ocupacional quien determinó si la habilidad funcional era adecuada o no. La variable de higiene bucal se recolectó mediante 
el Índice Cuantificado de Placa (ICP) tomado antes y después de cada uno de los cuatro controles. ${ }^{16}$

De igual manera, se incluyó la variable deterioro de cepillo que se midió por medio del índice de Rawls y colaboradores el cual determina el nivel de dispersión y el desgaste de las cerdas del cepillo ${ }^{17}$ (Figura 1). Esto se obtiene al medir la cabeza del cepillo y sus cerdas de la siguiente forma:

Wfs: máxima longitud del cepillo en la parte libre de las cerdas.

Was: máxima longitud de las cerdas ancladas a la cabeza del cepillo.

Wfe: es la anchura del cepillo en el extremo libre de las cerdas.

Wae: es la anchura de las cerdas en el extremo ancladas a la cabeza del cepillo.

Lo: hace referencia a la longitud de las cerdas.

Con estas mediciones se aplica la fórmula que se presenta a continuación:

$$
\mathrm{WI}=\frac{(\mathrm{Wfs}-\mathrm{Was})+(\mathrm{Wfe}-\mathrm{Wae})}{2 \times \text { Lo }}
$$

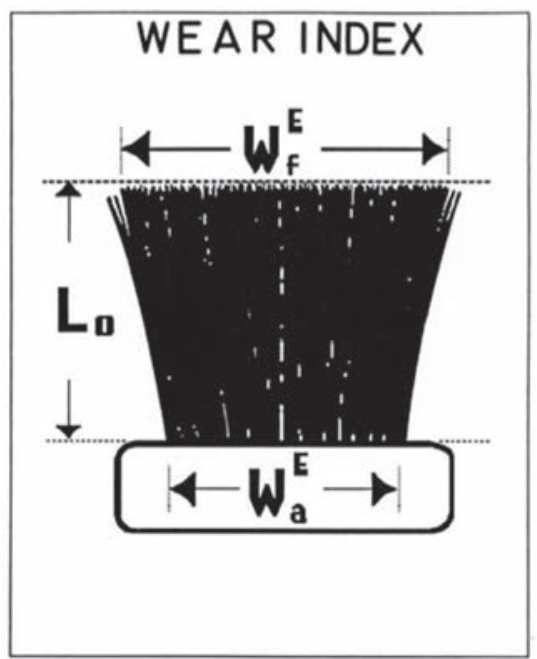

Figura 1. Ilustración del índice cuantitativo con sus respectivas medidas Wfs, Was, Wfe, Wae y Lo. Tomado de Rawls HR, Mkway-Tullouh NJ, Casella R, Cosgrove R. The measurements of toothbrush wear. J Dent Res 1989; 68: 1781 - $1785 .{ }^{17}$

El resultado de la ecuación se interpreta de la siguiente manera:

$0=$ No hay desgaste (deterioro entre $0 \%-25 \%$ ).

$1=$ Desgaste leve (deterioro entre 26\% - 49\%).

2 = Desgaste medio (deterioro entre 50\% - 75\%).

$3=$ Desgaste fuerte (deterioro entre $76 \%-100 \%) .{ }^{17}$
El estudio inició con la estandarización y prueba piloto en la que se determinó el nivel de acuerdo entre los evaluadores que alcanzó un Kappa de 0,71 catalogado como substancial. Se procedió a la recolección de las variables socio-demográficas, se realizó una actividad educativa orientada a enseñar el correcto cepillado reforzado con un video. Se le entregó el cepillo dental a cada escolar previamente enumerado con el mismo número de registro de cada instrumento.

La evaluación clínica inició con la intervención de la terapeuta ocupacional que efectuó un tamizaje donde observó la fuerza de muñeca, tono muscular, flexo extensión de muñeca y disociación motriz de todos los niños al valorar en ellos actividades grato motoras. La terapeuta ocupacional generó un diagnóstico sobre la funcionalidad y planeamiento en la habilidad motora fina acorde con su edad.

Posteriormente, se tomó el ICP antes y después de cada cepillado esto se efectuó durante una vez al mes durante cuatro meses. Se dispensó al niño el agente revelador en este caso la solución reveladora de marca Pro-Quident, se indicó que con su lengua distribuyera la solución reveladora sobre las superficies de los dientes. Se seleccionaron tres dientes y se dividieron tres tercios, en cada maxilar uno anterior y los otros dos en la zona posterior de cada lado; se revisó la superficie vestibular de los dientes superiores y la lingual de los inferiores. Se marcaron las superficies pigmentadas de los dientes seleccionados, sumándose el total de las superficies pigmentadas y se dividió por seis. El resultado obtenido se ubicó en uno de los tres rangos establecidos para el índice.

Luego de asignar y entregar cada uno de los cepillos dentales marca Colgate, se solicita al niño que cepille sus dientes. En este momento se recolecta la variable "actitud del niño a la hora de cepillarse" esta es la prueba situacional donde se observa el comportamiento que el niño refleja cuando cepilla sus dientes, si el niño estaba motivado y presentaba actitudes como mostrar interés por desarrollar la actividad, se catalogaba como una actitud positiva. De lo contrario, era negativa.

Ya terminada la actividad del cepillado se procedió a hacer las mediciones en el cepillo y calcular el índice de deterioro de acuerdo con los criterios mencionados.

\section{Análisis estadístico}

La base de datos se elaboró en Excel. ${ }^{18}$ El plan de análisis univariado incluyó frecuencias absolutas y relativas para las variables cualitativas y medidas de tendencia central y de dispersión para las cuantitativas. Para el bivariado se comparó tanto la higiene bucal como el deterioro del cepillo en cada 
control y para ellos se aplicaron la prueba t de Student pareada o el test Anova de medidas repetidas. Se correlacionó el nivel de higiene bucal con el deterioro del cepillo dental mediante el coeficiente de correlación de Spearman, se estableció la asociación del nivel de higiene bucal con las variables explicatorias y finalmente, se realizó un análisis de sobrevida frente al deterioro del cepillo en forma general y según el nivel de higiene bucal.

\section{Consideraciones éticas}

Este estudio se acogió a lo establecido en la Resolución 008430 de 1993, ${ }^{19}$ del Ministerio de Salud para el trabajo con menores de edad. Se solicitó la participación voluntaria de la institución como también de los participantes y sus acudientes. Se preservó en todo momento la autonomía, beneficencia, confidencialidad y privacidad de la información recolectada.

\section{RESULTADOS}

\section{Análisis univariado}

Variables sociodemográficas

Se evaluaron un total de 59 escolares con un promedio de edad de 7,1 \pm 0,7 años; el 52,5\% eran del sexo femenino.

\section{Análisis bivariado}

Seguimiento del grado de higiene bucal:

Los escolares registraron un promedio de placa dentobacteriana que representó un valor de higiene bucal de 2,6 $\pm 0,3$ en el primer control antes del cepillado y después de este fue $1,7 \pm 0,4$. Se observó que el antes vs. el después registraron diferencias estadísticamente significativas. Estos datos fueron similares en los cuatro controles realizados. Sin embargo, no se observaron diferencias en el promedio de la diferencia entre el antes y el después de los cuatro controles (Tabla 1).

Seguimiento del deterioro del cepillo:

Se observó un incremento en el promedio del deterioro del cepillo durante los cuatro controles. No obstante, no se observaron diferencias estadísticamente significativas al compararse estos promedios (Tabla 2).

Correlación de la higiene bucal y su relación con el deterioro del cepillo dental:

Al analizar la correlación entre el nivel de higiene bucal y el deterioro del cepillo se evidenciaron bajos niveles de correlación entre estos dos aspectos que oscilaron entre $-0,04$ y 0,35 (Figura 2).

Tabla 1. Grado de higiene bucal durante el seguimiento a los escolares de la Concentración Yira Castro en el segundo periodo del 2009

\begin{tabular}{|c|c|c|c|c|}
\hline Seguimiento & Grado de higiene bucal & $\mathbf{P}^{*}$ & Diferencia & $\mathbf{P}^{* *}$ \\
\hline Primer control & & $<0,0001$ & & 0,738 \\
\hline Antes & $2,6 \pm 0,3$ & & $0,9 \pm 0,3$ & \\
\hline Después & $1,7 \pm 0,4$ & & & \\
\hline Segundo control & & $<0,0001$ & & \\
\hline Antes & $2,2 \pm 0,5$ & & $0,6 \pm 0,4$ & \\
\hline Después & $1,7 \pm 0,5$ & & & \\
\hline Tercer control & & $<0,0001$ & & \\
\hline Antes & $2,2 \pm 0,5$ & & $0,6 \pm 0,4$ & \\
\hline Después & $1,6 \pm 0,5$ & & & \\
\hline Cuarto control & & $<0,0001$ & & \\
\hline Antes & $2,2 \pm 0,6$ & & $0,7 \pm 0,3$ & \\
\hline Después & $1,5 \pm 0,5$ & & & \\
\hline
\end{tabular}

*t de Student de medidas repetidas $\quad{ }^{* *}$ Anova de medidas repetidas

Tabla 2. Descripción del deterioro del cepillo durante el seguimiento en los escolares de la Concentración Yira Castro en el segundo periodo del 2009.

\begin{tabular}{lcccc}
\hline \multicolumn{1}{c}{ Seguimiento } & Promedio \pm D E & Mediana & Rango & P $^{* *}$ \\
\hline Primer control (59) & $10,1 \pm 5,6$ & 11 & $0-22$ & 0,731 \\
Segundo control (56) & $23,8 \pm 6,6$ & 22 & $11-44$ & \\
Tercer control (52) & $34,5 \pm 15,4$ & 31,5 & $11-85$ & \\
Cuarto control (51) & $43,7 \pm 20,6$ & 38 & $20-100$ & \\
\hline
\end{tabular}

** Anova de medidas repetidas 
ANTES

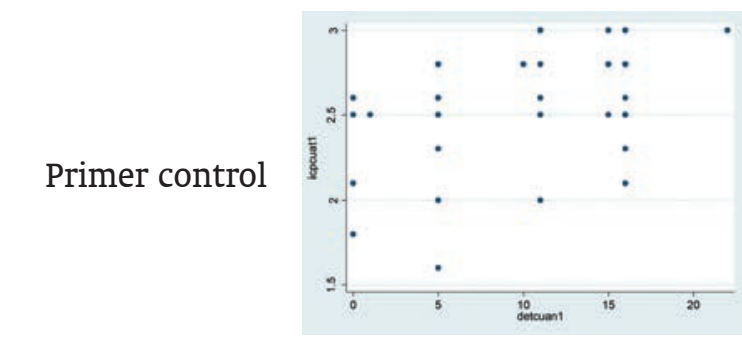

Coeficiente de correlación

Segundo control

Coeficiente de correlación

Tercer control

Coeficiente de correlación

Cuarto control

Coeficiente de correlación
0,351

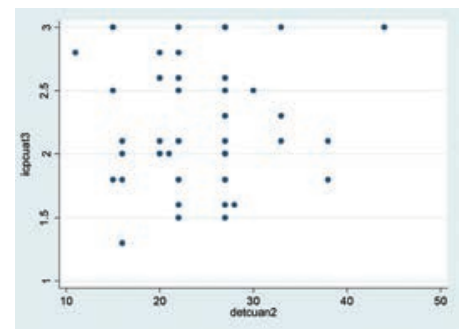

0,117

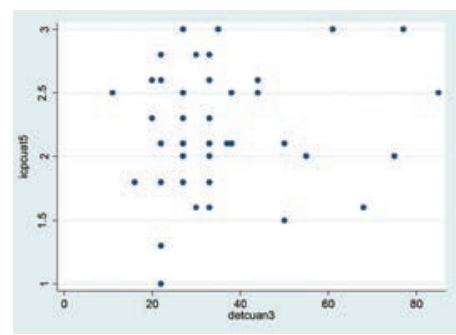

0,103

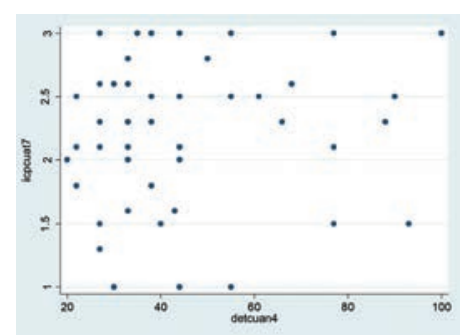

0,074
DESPUÉS

DIFERENCIA

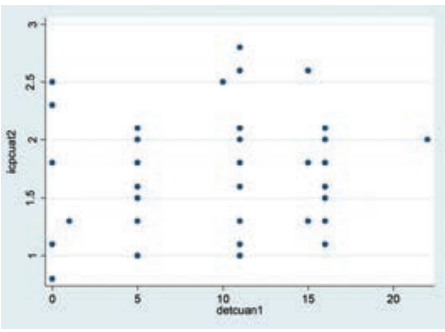

0,085
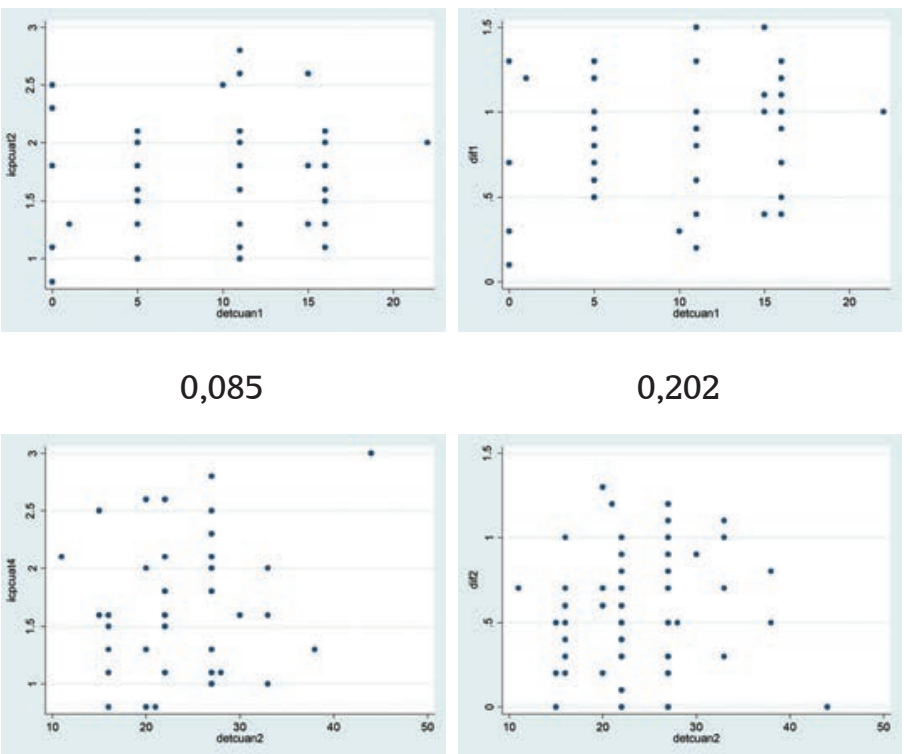

0,202

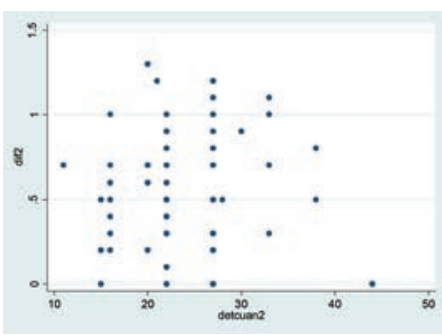

0,036

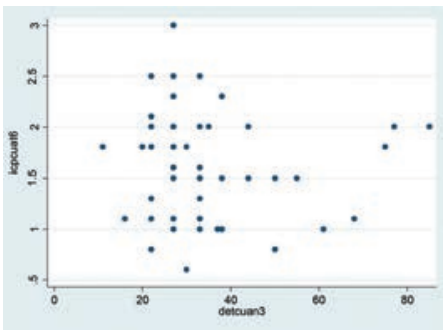

$-0,067$

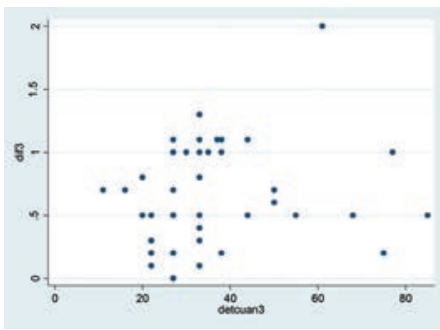

0,197

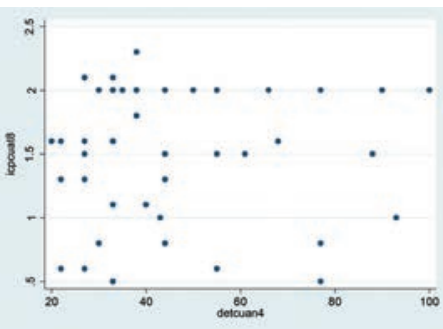

$-0,037$

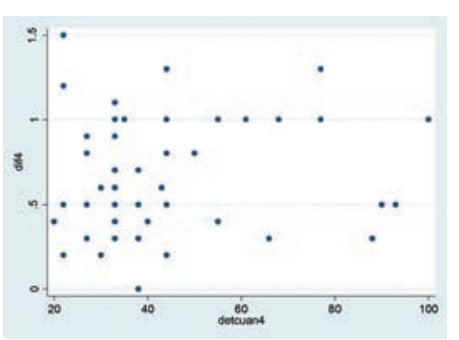

0,088

Figura 2. Correlación del nivel de higiene bucal según control y nivel de deterioro del cepillo.

Factores asociados a la higiene bucal:

Ninguna de las variables analizadas (sociodemográficas, relacionadas con la actitud, deterioro del cepillo dental y destreza manual) se asociaron en forma estadísticamente significativa con la higiene bucal. Sin embargo, es importante destacar que del total de personas que registraron una mala higiene bucal en el tercer control, el 5,6\% tenían un deterioro del cepillo fuerte y para el cuarto control el 13,2\% también registró este desgaste.
Es importante resaltar que el $25,5 \%$ de los escolares presentaron una motricidad fina no adecuada y el $45,1 \%$ de los cepillos registraron un deterioro mayor al $40 \%$. Quizás el aspecto más relevante es que del total de los escolares que se evaluaron en el antes del cuarto control el $74,5 \%$ registraban una mala higiene bucal fenómeno que fue consistente a lo largo del proceso (Tabla 3). 
Deterioro de los cepillos durante los cuatro meses:

Se evidenció deterioro definitivo del cepillo dental en una pequeña fracción a partir del segundo mes de control, cerca del $40 \%$ de los cepillos que se deterioraron en forma definitiva se observaron a partir del tercer mes de control; en el cuarto mes todos los cepillos estaban deteriorados (Figura 3).
Deterioro del cepillo dental según el grado de higiene bucal:

La velocidad de deterioro del cepillo se presentó más rápido en los sujetos que registraron mala higiene bucal comparada con los que registraron una regular higiene bucal (Figura 4).

Tabla 3. Análisis de los factores asociados a la higiene bucal.

\begin{tabular}{|c|c|c|c|c|}
\hline \multirow[b]{2}{*}{ Variable } & \multicolumn{3}{|c|}{ Higiene bucal } & \multirow[b]{2}{*}{$\mathbf{P}$} \\
\hline & $\begin{array}{c}\text { Global } \\
\text { n (\%) }\end{array}$ & $\begin{array}{l}\text { Mala } \\
\text { n (\%) }\end{array}$ & $\begin{array}{c}\text { Regular } \\
\text { n (\%) }\end{array}$ & \\
\hline Global & $51(100)$ & $38(74,5)$ & $13(25,5)$ & \\
\hline Edad (promedio \pm D. E.) & $7,1 \pm 0,7$ & $7,1 \pm 0,8$ & $7,1 \pm 0,6$ & $0,524^{* *}$ \\
\hline Sexo & & & & $0,940^{* * *}$ \\
\hline Masculino & $24(42,1)$ & $18(47,4)$ & $6(46,2)$ & \\
\hline Femenino & $27(52,9)$ & $20(52,6)$ & $7(53,8)$ & \\
\hline \multicolumn{5}{|l|}{ Mala actitud } \\
\hline Primer control & $1(2)$ & -- & $1(7,7)$ & 0,255 \\
\hline Segundo control & $2(4)$ & $1(2,7)$ & $1(7,7)$ & 0,456 \\
\hline Tercer control & $1(2)$ & -- & $1(7,7)$ & 0,265 \\
\hline Cuarto control & $1(2)$ & -- & $1(7,7)$ & 0,255 \\
\hline Deterioro del cepillo, primer control & & & & -- \\
\hline Sin deterioro & $51(100)$ & $38(100)$ & $13(100)$ & \\
\hline Deterioro del cepillo, segundo control & & & & $0,509^{* *}$ \\
\hline Sin deterioro & $27(54)$ & $21(56,8)$ & $6(46,2)$ & \\
\hline Deterioro leve & $23(46)$ & $16(43,2)$ & $9(53,9)$ & \\
\hline Deterioro del cepillo, tercer control & & & & 0,936 \\
\hline Sin deterioro & $10(20,4)$ & $8(22,2)$ & $2(15.4)$ & \\
\hline Deterioro leve & $32(65,3)$ & $22(61,1)$ & $10(76.9)$ & \\
\hline Deterioro medio & $5(10,2)$ & $4(11,1)$ & $1(7.7)$ & \\
\hline Deterioro fuerte & $2(4,1)$ & $2(5,6)$ & --- & \\
\hline Deterioro del cepillo, cuarto control & & & & 0,957 \\
\hline Sin deterioro & $6(11,8)$ & $4(10,5)$ & $2(15,4)$ & \\
\hline Deterioro leve & $31(60,8)$ & $23(60,5)$ & $8(61,5)$ & \\
\hline Deterioro medio & $8(15,1)$ & $6(15,8)$ & $2(15,4)$ & \\
\hline Deterioro fuerte & $6(11,8)$ & $5(13,2)$ & $1(7,7)$ & \\
\hline Deterioro $\geq 40 \%$ & $23(45,1)$ & $16(42,1)$ & $7(53,9)$ & 0,463 \\
\hline Motricidad fina & $13(25,5)$ & $9(26,7)$ & $4(30,8)$ & 0,716 \\
\hline
\end{tabular}

D. E.: Desviación Estándar. ${ }^{*}$ Exacto de Fisher ${ }^{* *}$ Prueba t de Student ${ }^{* * *}$ Test Chi $^{2}$ 


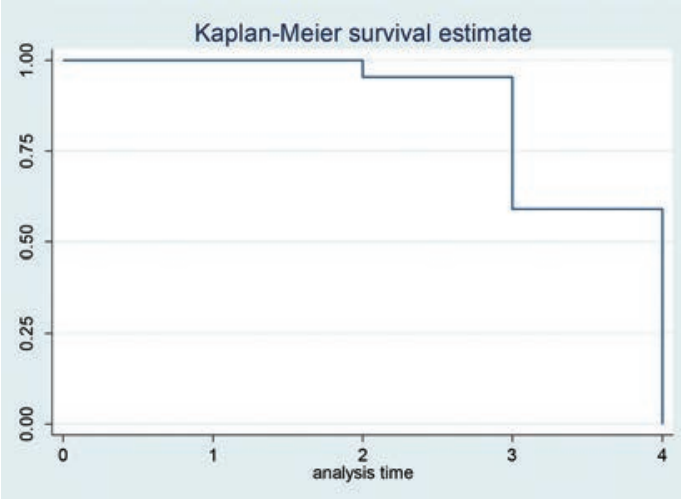

Figura 3. Análisis del deterioro de los cepillos expresado en meses

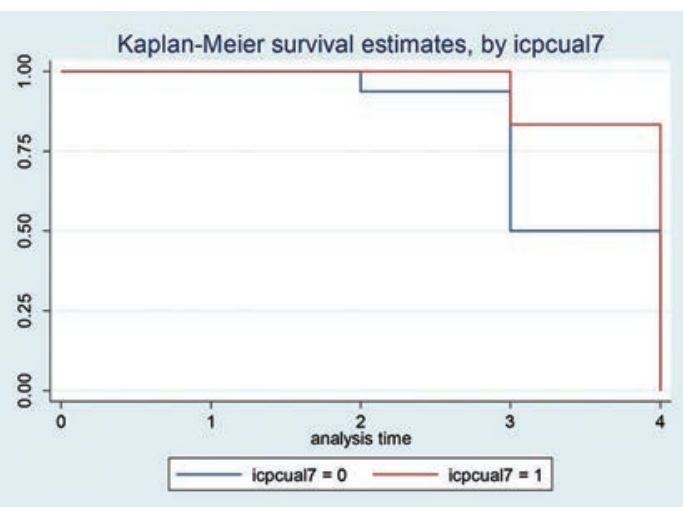

Figura 4. Análisis de deterioro del cepillo dental según nivel de higiene bucal expresado en meses.

\section{DISCUSIÓN}

La placa bacteriana es un factor predisponente a las enfermedades bucales, la mejor forma de contrarrestar su efecto es mediante su remoción que se logra principalmente con el uso diario del cepillo dental. ${ }^{3,4,5,20}$ El cepillado dental se considera una práctica, efectiva y de bajo costo por lo que realizar un buen cepillado sin lugar a duda mejora la salud bucal de cualquier tipo de población, por esta razón el objetivo este estudio fue investigar si el deterioro del cepillo dental tiene algún efecto en la remoción de placa bacteriana; para realizarlo se tuvieron en cuenta algunos factores relacionados con el cepillado y su potencial efecto como lo son la motivación, habilidad motora y el nivel de placa bacteriana antes y después de cepillarse.

En el primer control, el grado de higiene bucal antes del cepillado fue de 2,6 $\pm 0,3$ y después de realizar el cepillado fue de $1,7 \pm 0,4$, observándose diferencias estadísticamente significativas, son similares estas cifras durante los cuatro controles. Fue evidente que el promedio de higiene bucal de los escolares fue regular y malo a lo largo del estudio. Como lo sugiere la literatura la presencia de placa dentobacteriana en niños es alta según el reporte del III Estudio Nacional en Salud Bucal que mostró niveles de placa bacteriana del $98 \%$ en niños con edades entre los 5 y 12 años. ${ }^{20}$ De igual forma, un estudio realizado por González y colaboradores en niños escolarizados del corregimiento de la Boquilla en Cartagena de Indias durante el año 2004 reportó un alto índice de placa en el $79 \%$ de los escolares. ${ }^{21}$ Estos hallazgos corroboran que uno de los problemas es la mala higiene bucal que presentan los niños en el país. Por este motivo, es muy importante reforzar las estrategias orientadas a promover una mejor higiene bucal en la población escolarizada que reside en sectores vulnerables.

Durante el seguimiento de cuatro meses se observó un incremento en el promedio del deterioro del cepillo dental que es acorde con el uso dado a lo largo del estudio aunque no se presentaron diferencias estadísticamente significativas entre los promedios durante el seguimiento. Rawls y colaboradores creadores del índice utilizado encontraron relevancia en el tiempo de uso y el desgaste del cepillo y concluyeron que existen diferencias en el desgaste que hace cada individuo ${ }^{17}$ De igual forma, en un estudio realizado por Nava y colaboradores en México encontraron que el desgaste era proporcional al tiempo de uso y que este aumentó al llegar a los tres meses de uso. ${ }^{23}$

La correlación entre el nivel de higiene bucal y el deterioro del cepillo fue baja puesto que osciló entre $-0,04$ y 0,35 . van Palenstein Helderman y colaboradores estudiaron la remoción de la placa con un cepillo nuevo y uno viejo en niños con edades entre 7 y 8 años, concluyeron que no existía correlación entre el deterioro del cepillo y la higiene bucal. ${ }^{24} \mathrm{Tan}$ y Daly compararon un cepillo nuevo con uno que tenía un tiempo de uso de tres meses y su relación con la remoción de placa, encontraron que no existía diferencias estadísticamente significativas entre éstos. ${ }^{10}$

Cabe destacar que se encontraron diferencias entre los cursos de segundo grado ya que en uno la directora del grupo mostró más interés en que los niños se cepillaran diariamente una vez terminado el descanso; por esta razón, es posible que este grupo usara más el cepillo. Adicionalmente, es importante anotar que no se encontraron métodos validados para medir la motivación de los niños al realizar el cepillado. Al analizar los resultados del presente trabajo se cree que la prueba situacional no parece ser el mejor método para analizar esta variable; se sugiere analizar la posibilidad de abordar más a fondo esta variable y encontrar un mejor método de medición puesto que se sabe que la motivación no hace parte de la personalidad de los individuos 
si no que es un estado y puede verse afectado por factores ambientales, personales y conductuales. ${ }^{11,25}$ Así mismo, se recomienda utilizar una muestra de niños mayores de 7 años donde su actividad motora se encuentre más desarrollada como lo refiere Meritano que concluye que los niños mayores de 11 años tienen un mejor manejo de las técnicas de cepillado y, por ende, una mejor higiene bucal. ${ }^{26}$

La habilidad motora se consideró una variable importante ya que un cepillado comprende movimientos coordinados de mano y muñeca. Se observó que el 25,5\% de la población objeto de estudio presentó problemas en su habilidad motora y se evidenció un deterioro del cepillo mayor al $40 \%$. Ojeda y colaboradores evaluaron la asociación entre la capacidad física funcional (CFF) y la higiene bucal y encontra- ron que la habilidad motora no registró una relación estadísticamente significativa con el nivel de higiene bucal, sin embargo, llamó la atención la relación estadísticamente significativa con las alteraciones musculares y su estrecha relación con la función motora en niños. ${ }^{27}$

El 40\% fue el punto en el que se estableció que existía un deterioro definitivo del cepillo, éste fue establecido por consenso entre los investigadores puesto que se observó un deterioro marcado en las cerdas del cepillo, como se evidencia en las imágenes de la Figura 5. Este punto de corte se debe analizar con reserva y para estudios futuros se recomienda establecer varios puntos de corte para el análisis con el fin de obtener resultados más consistentes.

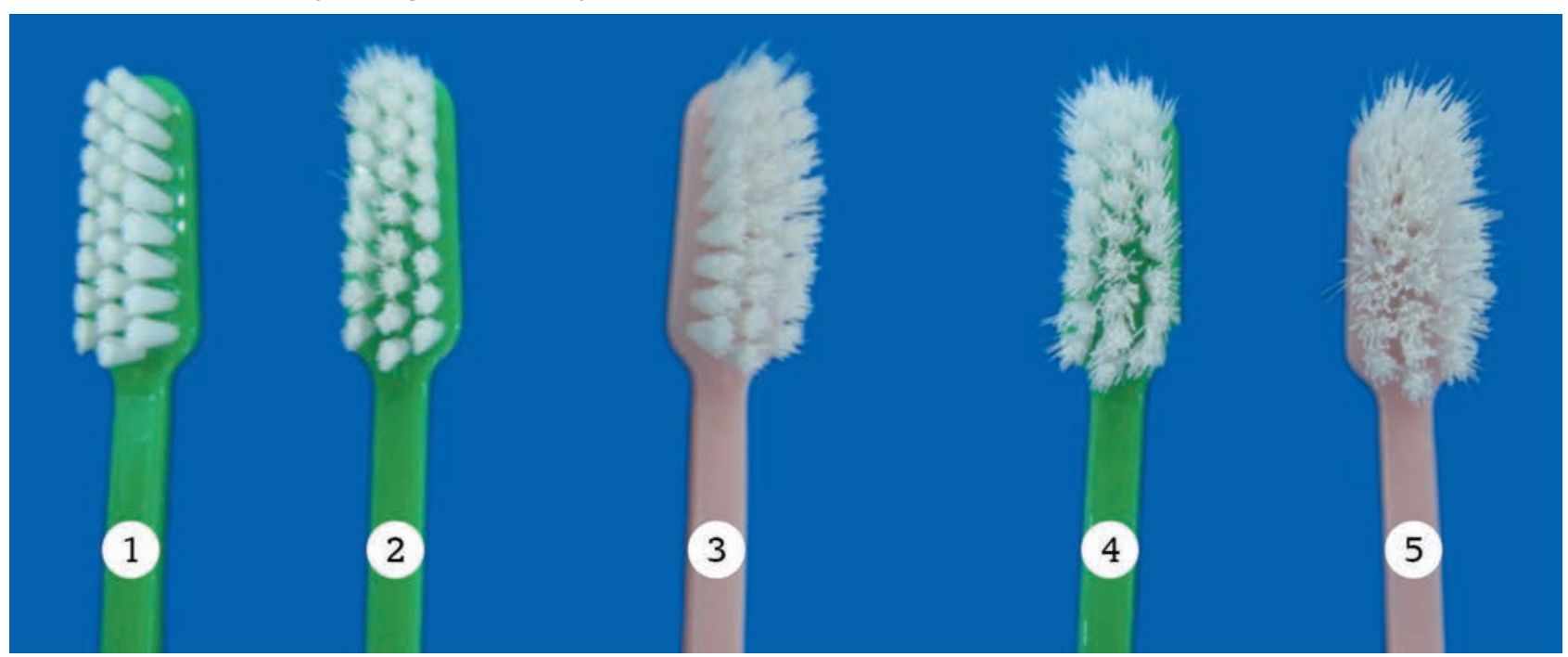

Figura 5. Imágenes sobre el deterioro del cepillo. Los valores corresponden a: $1=$ cepillo casi nuevo con un deterioro del $8 \%$, $2=$ cepillo con deterioro del 16\%, 3 = deterioro del $28 \%, 4$ = deterioro del $43 \%$, 5 = deterioro del $78 \%$.

En cuanto al tiempo que indican las casas comerciales y la literatura para realizar un cambio del cepillo dental se encontró consistencia en lo reportado por diferentes autores. En el presente trabajo, un 30\% de los cepillos dentales se catalogaron con deterioro total a los tres meses y un $100 \%$ a los cuatro meses. Por tanto, estos resultados coinciden en lo sugerido por la evidencia al indicar que es conveniente hacer un recambio del cepillo a partir del tercer mes. $8,10,17,23,28,29$

De acuerdo con los resultados obtenidos en este trabajo, es necesario orientar las campañas para mejorar y facilitar a los niños una técnica de cepillado que sea más efectiva y acorde con cada individuo según su nivel de desarrollo ya que más que promover el hábito es importante lograr que se haga de una buena manera y este cumpla su finalidad. Puesto que los altos índices de placa predisponen a las enfermedades bucales como lo son la caries dental y la enfermedad periodontal. ${ }^{3-9,30}$
De igual forma, es importante tener en cuenta que la vida útil de un cepillo utilizado dentro del ámbito escolar podría ser más largo, puesto que su uso no es contínuo, sólo durante la jornada escolar. Sin embargo, es importante analizar los aspectos relacionados con la contaminación microbiana, el mantenimiento y la disposición adecuada del cepillo dental para lograr una vida útil más prolongada. Además, es necesario monitorear a los escolares que registran un marcado deterioro del cepillo lo que podría determinar la necesidad del recambio.

Se concluyó que no se encontró relación alguna entre el deterioro del cepillo y la higiene bucal de los escolares. Por tanto, el deterioro del cepillo no influyó en el grado de higiene bucal de los niños evaluados.

\section{Agradecimientos}

A los escolares, profesores y directivos de la Concentración Yira Castro por su colaboración en la realización de este estudio. 


\section{BIBLIOGRAFÍA}

1. Maserejian NN, Taveres MA, Hayes C, Soncini JA, Trachtenberg FL. Prospective study of 5-year caries increment among children receiving comprehensive dental care in the New England children's amalgam trial. Community Dent Oral Epidemiol 2009; 37: 9 - 18.

2. Martignon S, Gonzales MC, Santamaria R, Jacome L, Muñoz Y. Oral health workshop targeted at 0.5 year old deprived children's parents and caregivers: effect on knowledge and practices. J Clin Pediatr Dent 2006; 2 (3): 980 - 983.

3. Reyes ES, Forero L, Rodríguez MJ. Impacto de la educación en la salud oral en una población escolar de la aldea infantil de un órgano gubernamental sos de Santander, Floridablanca determinando la influencia de higiene oral y el índice gingival. Ustasalud 2007; 6: 93 - 100.

4. Blanco N, González ML, Torres IC. Cepillos dentales en la prevención oral [Trabajo de Grado]. Bucaramanga: Universidad Santo Tomas; 1996.

5. Jackson RJ, Newman HN, Smart GJ, Stokes E, Hogan JI, Brown C, Seres J. The effects of a supervised tooth brushing programme on the caries increment of primary school children, initially aged 5-6 years. Caries Res 2003; 39: 108 - 115

6. Löe $\mathrm{H}$. Oral hygiene in the prevention of cries and periodontal disease. Int Dent J 2000; 50: 129 - 139.

7. Rimondilin B, Bernardi F, BEZC. Self-preventive oral behaved in on Italian on university student population. J Clin Periodontol 2001; 28: 207-211.

8. Daly C, Marshall R, Lazarus R. Australian dentist's views on toothbrush wear and renewal. Aust Dent J 2000; 45 (4): 254 - 256

9. Van der Weijden GA, Hioe KPK. A systematic review of the effectiveness of self-performed mechanical plaque removal in adults with gingivitis using a manual toothbrush. J Clin Periodontol 2005; 32 (suppl.6): 214 - 228.

10. Tan E, Daly C. Comparison of new and 3-month-old toothbrushes in plaque removal. J Clin Periodontol 2002; 29 (7): $645-650$

11. Harris NO, García F. Odontología Preventiva. Segunda Edición. Editorial Manual Moderno: México; 2005.

12. Concha SC. Evaluación de la asociación de una buena higiene oral con hábitos de autocuidado adecuados en escolares vinculados a dos concentraciones de Bucaramanga y su área metropolitana. Ustasalud 2005; 4: 91 - 98.

13. Weinstein P, Rosamund $\mathrm{H}$, Benton T. Motivating mothers to prevent caries: Confirming the beneficial effect of counseling. J Am Dent Assoc 2006; 137: 789 - 793.

14. Weinstein P, Rosamund $\mathrm{H}$, Benton $\mathrm{T}$. Motivating parents to prevent caries in their young children. One-year fin- dings. J Am Dent Assoc 2004; 135: 3016 - 3025.

15. Sánchez R. Manual de desarrollo motor grueso y fino en niños escolares hiperactivos. 2005; p. 205 - 235.

16. Pieschacón MP. Programa piloto de odontología preventiva con escolares del municipio de Bucaramanga [Trabajo de Grado]. Santiago de Chile: Universidad de Chile; 1998.

17. Rawls HR, Mkway-Tullouh NJ, Casella R, Cosgrove R. The measurements of toothbrush wear. J Dent Res 1989; 68: $1781-1785$

18. Microsoft Excel 2003. Microsoft Corporation.

19. República de Colombia, Ministerio de Salud, Resolución No 008430 del 4 de octubre de 1993.
20. American Academy of Pediatric Dentistry. Guideline on Infant Oral Health Care. Pediatr Dent 2004; 24: 132 - 136.

21. República de Colombia. Ministerio de Salud. III EstudioNacional de Salud Bucal. Centro Nacional de Consultoría. Colombia, 1999.

22. González FD, Alfaro L, Nieto C. Relación placa bacteriana y caries en un grupo de niños escolarizados entre 5 y 14 años de la población de la Boquilla - Cartagena en el año 2004. Duazary 2007; 4: 119 - 126.

23. Nava J, Zárate C, Meza L. Medición del desgaste de cepillos dentales en México. Práctica Odontológica 1999; 20:7 - 18.

24. van Palenstein Helderman WH, Kyaing MM, Aung MT, Soe W, Rosema NA, van der Weijden GA, van't Hof MA. Plaque removal by young children using old and new toothbrushes. J Dent Res 2006; 85: 1138 - 1142.

25. Aguirre J, Fardón F. Como medir la motivación [en línea]. Universidad Nacional Autónoma de México. URL disponible en: http://www.ideasapiens. com/psicologia/cognitiva/ instrumentos_\%20medicion_\%20d_la\%20motivacion_. htm

26. Meritano M. Habilidad de cepillado eficaz relacionada con la destreza manual. Práctica Odontológica 1990; 11: 11 $-12$.

27. Ojeda WA, Sánchez JL, Concha SC. Evaluación de la asociación entre la capacidad física funcional y la higiene oral en los niños y las niñas que acuden a la consulta odontológica a las clínicas integrales del niño de la Universidad Santo Tomás. Ustasalud 2007, 6: 29 - 36.

28. Hogan ME, Daly CG, Curtis BH, Comparison of new and 3 month-old brush heads in the removal of plaque using a powered toothbrush. J Clin Periodontol 2007; 34: 130 $-136$.

29. Kreifeldt JG, Percy H,Hill, Louis J.P Calisti L. A systematic study of the plaque removal efficiency of worn toothbrushes. J Dent Res 1980; 59 : 2047 - 2055.

30. Weinstein P, Rosamund H, Benton T. Motivating mothers to prevent caries: Confirming the beneficial effect of counseling. J Am Dent Assoc 2006; 137: 789 - 793.

\section{Correos electrónicos de los autores:}

Liliana Patricia Acevedo Piñeres: liliana-acevedo@hotmail.com Clara Johana Caicedo Rico: claris2486@hotmail.com Claudia Milena León Castro: claudimile60@hotmail.com Sonia Constanza Concha Sánchez: sococosa@yahoo.com 